\title{
MEASURING YOUTH PERCEPTIONS IN THE DIRECTION OF BRANDS ON DIGITAL MEDIA USING NETNOGRAPHY
}

\author{
Raheel Farooqui \\ Senior Lecturer Bahria University \\ Raheelfarooqui.bukc@bahria.edu.pk \\ Sana Azher \\ Senior Lecturer Bahria University \\ SanaAzher.bukc@bahria.edu.pk \\ Anita Laila \\ Assistant Professor Bahria University \\ Anitalaila.bukc@bahria.edu.pk
}

\begin{abstract}
This study explores and observe the motivations of youth in digital culture which influence themto follow and interact with brands on digital media through netnography. This technique tries to adopt patron notion of youth in digital culture which influence them for youth follow brands official pages for the purpose of being up to date with brands offerings for purchase and repurchase. This studies cram changed into qualitative in nature, primary and secondary source of codes selected examined and interpreted. The data by using structured interviews (open-ended questionnaire) has been supported by relevant secondary literature that will support for conducting qualitative research based on netnography. The online digital media in Pakistan Karachi has on itssignificance, it's evolving everyday but with quite difficulties like time comments youth targetedfood brands pages were found to be highly interactive, quite extensive amount of likes and even comments were seen on various posts. Comments included people suggesting others for the products and deals, also people actively shared their feedbacks for the products. This studies studythoughtful beneath the parameters of online digital media, changing time era and great supported belongings writer controlled to provide a reason behind the comprehensive functionality of the study.
\end{abstract}

Keywords: youth, digital culture, social media platform, qualitative research, Netnography

\section{INTRODUCTION}

In this era of virtual networks and hi-tech communication business has become quite dynamic due to increasing dependability of consumers on technology and social media is one major technological platform which has caught most of the consumers attention, which even has developed its own culture which is named as Digital Culture. Digital Culture represents the shared beliefs, practices and knowledge of members of interactive digital networks which can reconstruct cultures in the tangibleworld or develop new and different kind of practices and cultural thoughts shaped by digital networks. So, social media has made it easier to express your opinion, such a feature of social media is powerful that it has even made it possible for nations to bring political revolutions in their countries. Social media is also being used for the educational purpose as well. Many people became entrepreneurs by using social media. It won't be wrong to say that social media is a world of opportunities for everyone in the society to interact and share with each other. Hence, there are massive opportunities for marketers as well to target and interact with their suitable target market. Few of the studies which were conducted in recent past have also highlighted this fact that in order to achieve success in brand management, it is crucial in this time to understand the behavior of consumers' and the way they interact in online virtual world (Singh, 2012).

According to a research, the number internet users all over the world has now reached to the figure of approximately 4 billion and this figure contributes as $60 \%$ of the world's total population and this is the fact which is resulting in a complete transformation of different social aspects including social interactions, social associations and consumers empowerment (Acar \& Puntoni, 
2016). According to another study which found that about 53 percent users of social media expressed that they enjoy the advertisements of different brands on their social media network, and 46 percent were also inclined to follow brands through social media. So, in this current technological era it is highly pivotal for academicians and marketing practitioners to study and understand the intensity and the impact of these kinds of changes occurring in the society (Simmons, 2008), particularly which are related to branding and promotion, as it can be observed that many consumers now a days are inclined towards different channels in the online space where they can interact with the brands. So, such outcomes emphasize on the great deal of importance towards attaining a detailed understanding of these interactive relationships between brands and their consumers.

The evolution of social media has triggered a great need for the marketers to rethink their marketing strategies because currently market is driven by co creation of brands through informal communications among the authors on which marketers has no control. In this case, brand in initial stages may symbolize the story commercialized by the marketer but eventually it absorbs the stories shared by the consumers in terms of their personal opinions and experiences which at certain point in time begins to impact and decompose the brand identity. Therefore, it is seen that social media has played a role in shifting of power from media producers to the consumers, as they can now create and publish the content at various platforms which is not only uncontrollable for the marketers but also even unapproachable as well at sometimes (Peters, Chen, Kaplan, Ognibeni, \& Pauwels, 2013).

Up till now a quite limited amount work has been done on the subject brand equity in the perspective of marketing at social media and its effectiveness, even though there are just only few noteworthy studies available on this perspective. A rapid evolution of marketing and education is seen in the virtual environment, however this change in the way of doing business at one end is facilitating as cost reduction in doing business but on the other end it is turning into a threat for the existing players in the market because this is encouraging new player to enter the market, those who were restricted previously from entering the competition may be just due to inaccessibility to the appropriate geographical locations for the business (Kim \& Ko, 2012).

In this context, this paper addresses youth's (also known as generation Z) motivations in developing relationships with brands in the online environment. Generation $\mathrm{Z}$ is one of the most challenging cohorts for the marketers now a days. Understanding generation $\mathrm{z}$ is crucial because this era belongs to them. Now, this cohort is considerably difficult to deal with because they are much different in terms of decision making and lifestyle then the previous generation because of the availability of enormous resources. They are quite smart and well informed about different aspects of the world. They have got abundant resources as compared to previous generations in terms of information, networking and accessibility. Social media plays a vital role in their decision making. They can use social media for the purpose of networking, to attain knowledge, to attain brand awareness and even interact with brands, sharing their feedbacks about different products and services; playing games; contributing to or attaining know how on religious aspects; expressing their patriotism, love, likes, belief, religious affection and at the same time expressing their hatred, dislikes, contradictions as well. Generation $\mathrm{Z}$ also even recognized with the name of 'Internet generation'. People belong to this generation are said to be as network youth because they have access to become member of various network groups, they are far from similar to the prior generations. Considering the fact that they can communicate with anyone regardless of the long distances, it is assumed that they can manage to live alone. It can also be proposed that they possess multitasking skills. According to some expert's generation Z's attention span is quite short which is due to immense dependency and high involvement with technology (Chicca \& Shellen, 2018a).

\section{Qualitative Approach}

This study has applied netnography because to analyze and observe the motivations of youth in digital culture which influence them to follow and interact with brands on digital media through netnography as it relates to the purpose of the study which is motivation of youth.

Problem Statement (Purpose)

Lack of information to attract and access youth segment through social media for the purpose of advertisement and customer relationship management.

\section{Research Question}

What are the motivations of youth segment which influence them to interact with brands on social media? 


\section{REVIEW OF LITERATURE}

In recent past a research was conducted on the motivations which uses and gratification theory was applied to conduct a detailed investigation on motives behind using digital media. According to this research, the most common theme emerged out was "social interaction" and the other themes were entertainment, communication benefit, expression of opinion, information seeking, relaxation, surveillance or information about others and convenience utility (Whiting \& Williams, 2013).according to another study uses and gratification theory is highly effective to be used as a tool to understand the undiscovered motives of the mothers for their engagement with the brands on digital platform. This theory can also examine the reasons of usage of a certain channel and the gratification obtained from its usage. By using this theory three major aspects of digital media are discovered including: information seeking, personal identity enrichment, and diversion (Blumler, 1979; Jensen, 2013). Netnography is an online research method that studies user interactions on the internet and reveals the story underlying the conversations over a digital platform. It is useful in studying complex social phenomena from where thematic inferences about users' opinions can be drawn (Kozinets, 2002). Specifically, it offers insights into the exposure of consumers to actual content that is necessary to investigate the influence of content characteristics on engagement (Voorveld, 2019). Domestic cricket leagues and the associated sport clubs have gained prominence in the past decade with the emergence of the Indian Premier League (IPL) in 2008. IPL is the most prominent domestic cricket league in the world, and players from major cricket playing nations participate in this league. In a short span of time, the popularity of IPL clubs has grown exponentially, and some IPL clubs have more than 10 million fans following the official fan pages on different social media platforms. Given its prominence and rapid growth, IPL was selected as the focus of the netnography study. A total of eight clubs have participated in the IPL regularly. As two of the clubs, Chennai Super Kings (CSK) and Rajasthan Royals (RR) were suspended during the 2015 and 2016 season, the remaining six cricket clubs' 1 social media pages were considered for investigation. Of all the social media sites, Facebook has the largest active user base. Facebook has more users than the combined users of Twitter, What Sapp, and Instagram (CNBC Social Media, 2014). This makes it imperative for sport clubs to consider Facebook as an essential platform to enhance fan engagement (Yoshida et al., 2018). Online groups that show active interaction by a large number of individuals are considered an appropriate source for data collection (Kozinet, 2002). On the official Facebook pages, sport clubs possess well-organized posts over an extended timeline and serve as a potential platform for the sport clubs to connect with their fans. Hence, Facebook was chosen as the source for data collection.

Various other researchers have also used uses and gratification theory to investigate about the digital culture and what are the motives behind usage of social media for example one study discovered about college student's usage of social media sites in digital culture which reported that "staying connected with friends" as one of the motive of engagements with social media sites (Raacke \& Bonds, 2008). A descriptive study was carried put to find out the reasons behind people's engagements at user-generated sites like Wikipedia, Youtube and MySpace and classification which was initially provided by this study was a quite fascinating information which may be empirically applicable and rewarding for consumer or brand management in social media (Shao, 2009). These were the initial attempts from different researchers to find out how people behave indigital culture and what are motives which influence them to engage with certain sites and groups in social media but there is still a lot to explore about digital culture as it is expanding at a fast pastin all segments of the world with a lot of opportunities for the businesses lying undiscovered in itsvirtual environment. There are various aspects of discussed in this literature which proofs that whyit is actually considered as a culture. It is said to be emerging as digital culture.

Entertainment is a part of a culture and digital culture is full of entertainment. A researcher explained entertainment in digital culture as an outcome of fun and play produced as part of the experiences of social media (Muntinga, Moorman, \& Smit, 2011). Even there is an insight sharedby a research that users of social media are pleasure seeker, they use this digital platform for the purpose amusement and entertainment, and they actually enjoy the social media experience Accordingly, it was also observed that entertainment is even one of the most influential motives for using usergenerated sites as well (Shao, 2009). Also, various studies like, (Muntinga et al., 2011) discovered that people at social media engage with branding content for the purpose of pastime, relaxation and 
amusement.

Information sharing is one of the most crucial parts of any culture and digital culture also has its own of way of information sharing. Currently, digital media is the most updated medium for the news or information about any hot affair or even for the purpose of searching for products (Naaman, Becker, \& Gravano, 2011). Consumers prefer digital media to obtain any kind of information. They consider digital media as most trust-worthy platform for getting information rather any promotional activities carried out on commercialized mediums in which corporate sponsored information is shared (Mangold \& Faulds, 2009).

A study has classified sub motives behind attaining information on digital media which are: Knowledge, inspiration, surveillance and pre-purchase information. Where Knowledge is explained as information about brands, it is observed that people take the benefit from other consumers' know how and expertise with intent to get more details about the brand or product. Inspiration is referred as situations in which consumers come up with new ideas by attaining brandrelated information which means they get inspired from brand related information. For example, consumer get idea of what he/she should wear by looking at or getting inspired by an image sharedby a brand. And surveillance is described as noticing other activities and staying updated about other people's activities. Pre purchase information is about making a well-informed buying decision by reading about product details, reviews of product, discussions, groups and communities related to different brands (Muntinga et al., 2011).

A research was conducted in recent past to explore the motives which influence the mothers in digital culture to interact with brand pages on digital media. This research found eight motives which influence the mothers to follow and interact with brands pages on digital media sites like facebook \& instagram and those eight motives are: information, knowledge-seeking, maintaining brand relationship, social interaction, entertainment, self-expression, social influence and communication. These results are beneficial for the marketers who needs market their product the mother's segment through digital media. Study also found that there has been a great change in the behavior of consumer as compared to the one elicited by prior studies (Teresa \& Jose, 2019).

With the fast-paced development and expansion of digital culture through digital media there are various aspects and segments needed to be explored. However, this study is going to explore the most important and significant segment of the current time which is generation Z. So, GenerationZ is the epicenter of this research paper, on which a lot of research now has already done specially in the field of marketing but still a lot more is yet to be explored about this segment. By 2020, this segment is expected to become so big that it will share about $40 \%$ of the population of all consumers in US (Kelly, Kerr, \& Drennan, 2010). It can be easily speculated that this generation is going to become a challenge for marketers due to the fact that they are brought up in the fast-changing environment of innovation. This segment is capable of multitasking due to the busy schedule of their daily routine, they are found to be highly creative, independent and expressive; they do not like to wait for longer duration rather prefer fast processing and almost always stay connected via different IT based communication devices. They don't like waiting for long, they want to get everything wherever they want and in an instant way. This young segment is so smart that they easily sort out and give their attention to only creative and well-articulated brand messages and exclude those messages which are irrelevant and unexciting. Their understanding and knowledge about brands are good that they pointing out reliable and unreliable brands is like piece of cake for them According some studies, this generation which was born starting from 1997 is given titles like "screenager" or "screen addicts" because they have opened their eyes in a worldwith instant and continuous connection to internet and digital media (Rodney, 2017).

This generation has more information instantly available then any of the previous generations, all the information is at fingertips for them. They have grown up in a world full of technology like computer systems, mobile devices like laptops, tablets, smart phones, internet, interactive screens, digital world filled with social media site (Facebook, google+,), instant messaging apps (Imo, WhatsApp, WeChat), images sharing sites (Pinterest, Instagram, Flickr), video sharing platforms (Youtube, Vine), micro blogs (Tumblr, Twitter) and various other Hi-tech communication devices and platforms, all of which makes them more smart in decision making, and makes various aspects of their life easier, for example they can easily socialize through digital media and make well informed purchase decisions (Rodney, 2017; Stokes, 2013). Therefore, it is crucial to attain more 
knowledge and understanding about this generation's behavior in digital culture.

Digital media provides a platform full of opportunities for the marketers to access their target market in their virtual groups and also strengthen their relationship with the consumers (Kelly, Kerr, \& Drennan, 2010). Now, digital media has changed the marketing scenario to great extent that brand's content creation, distribution and consumption is all changed now and power influencing the brand image is also shifted towards consumers because now they share content related to brand on digital media.

According to a study relationship among brands and their consumers can be developed just like the relationship between two persons. Researcher specifically emphasize on the aspect of interdependence among both the partner, it was pointed out that a brand needs to behave actively and become a contributing member in the relationship. Now, digital media has provided new andeffective venues of communication for the brands and made them more active than ever.

Through digital media brands now can even interact with consumers at individual level directly. Moreover, marketers perceive digital media as more effective way for implementing relationship marketing activities. Therefore, in order to build a long-term and genuine relationship with their audience, marketers are increasing their marketing and advertising activities over digital media (Teresa \& Jose, 2019; Fournier, 1998)

\section{Staying informed}

So, for the youth the most basic motivation for following the brands on social media was to keep them updated about new products and offerings of brands. As per the respondents, they follow different brands pages most importantly to stay aware about the new products launched by the brands and brands special offerings like sale and deals. They also follow different cinema's pages to stay aware about new movies and their show times as well.

\section{Referred brands}

Respondents highlighted that they easily start following those brands which are referred by others rather than those which are advertised to them from the Site like Facebook. So, they trust the referrals provided by their peers or anyone whom they perceive as knowledgeable in that particularcategory. However, they don't trust the auto-channeled advertisement and they don't like to wastetime clicking on those ads.

\section{Feedback power}

Another motivation was found as expressed by some of the respondents that it gives power to them so that if a brand or seller misbehaves or do something wrong then have it as a platform raise voice against them. So, social media now gives power to consumer against seller so that they cannot be mistreated or mislead or exploited. If a consumer put a bad comment on social media, it can affect sellers business with a great intensity even big brands are do get affected.

\section{Entertainment}

Respondents shared that they like participate in activities shared by the brands which serve as a sort of entertainment for them. They said they enjoy participating in various games and contests designed by the brands; and try to win those contests then sharing with their peers about their experience.

\section{Self-expression}

Following brands is also way of self-portrayal for the youth because they believe that just becausetheir activities can be seen by others on their profile. So, their likes, comments and recommendation also do create an image about them in front of others on their profile. So, while following and engaging with the brands they also take care of what image this act might portray about them. And sometimes they use it as a tool like for example by liking and engaging with some class-oriented brands.

\section{Pre-purchase information}

They also use social media to get recommendation and suggestions related which brand or company to choose for particular product or service. As, now there are various groups on Facebookwhich used for this purpose like there pages food recommendations on which people share their experiences with different food brands and also guide those who ask for recommendation.

\section{METHODOLOGY}

In this analysis researcher uses netnography by the views of participants because it examines the motivations of youth in digital culture which influence them to follow and interact with brands on 
digital media. The researcher collected the data by using structured interviews (open ended questionnaire) and will be supported by relevant secondary literature that will support for conducting qualitative research based on netnography. For inferring the concepts, open coding, axial coding's well as selective coding of narrative data will be the next step that will be followedamong different constructed categories as well. Propositions will be based on relationship between and among categories. After the first relational closeness, that is, group's capacity, the iterative process will be collecting data till the saturation of categories. Informations was collected in two phases. In first phase nentnography was carried out by monitoring 12 facebook groups for about amonth. In second phase in depth interviews were conducted from BBA students of Iqra University.

The analysis of memos prepared during the data collection and data interpretation will finally leadto substantive and formal theory. Similarly, techniques which is used for Qualitative study consist of interview, document analysis as well as observations. Triangulation-placing together of numerous forms \& pieces of information -which can provide helping hand for better Interpretation \& analysis of a situation. Agreeing to Patton (1990).

\section{Field Work}

According to Kozinet (2002) a qualitative research method known as netnography is the best method a researcher can employ to study the cultures and groups developed in the digital media; this method uses ethnographic techniques to study cultures at digital platforms. Netnography helps researchers in observing online interactions in their natural setting (Momoko, Paul, \& Geoffrey, 2019; Kozinets, 2010, 2015). The reason of implementing this technique was to observe how studied segment behave in digital culture of social media and gather more detailed information.

In order to carry out netnography, researcher at first enlisted 25 groups on Facebook which were related to youth. After enlisting 25 groups, these groups were evaluated on the basis of criteria recommended by Kozinet and his criteria suggest that each group must possess attributes including: active, relevance, considerable no. of members, interactive, richness of data and heterogeneity (Kozinet, 2002). After this evaluation process only 12 Facebook groups qualified on the kozinet's criteria, and those groups were selected for further process. These groups were monitored over the period of a month. Observations were conducted on daily basis, researcher downloaded images, took screenshots of different conversations for further analysis.

\section{In-depth Interview}

Interviews were conducted through asking open ended questions. First part of the interview included questions related to their education, hobbies and employment (if any) to understand their lifestyle. Second part included questions related to their activities over digital media, some questions were particularly related to brands following over Facebook.

\section{Sample Size}

According to Creswell book (2013) sample size should be 20 to 25 participants. But researcher have taken interview from four respondents then saturation arrives in this case researcher doesn't go beyond four respondents. Data collection.

Information was collected in two phases. In first phase nentnography was carried out by monitoring 12 Facebook groups for about a month. In second phase in depth interviews were conducted from BBA students of Iqra University.

\section{DATA ANALYSIS \\ Netnography}

As a result of netnography it was observed that youth follow brands official pages for the purpose of being up to date with brands offerings. However, a difference in behavior was observed for different category of products like in youth targeted clothing brands' pages most of posts attained more likes but very few comments i.e. about 0-12 comments per post until and unless admin provoked them to interact by posting any interaction based prize winning games or even non prize winning games on such a posts significant level of interactions were seen. Very few posts on clothing brands were able attracted higher number of comments and most of those comments were bout price. Whereas, on youth targeted food brands pages were found to be highly interactive, quite extensive amount of likes and even comments were seen on various posts. Comments included people suggesting others for the products and deals, also people actively shared their feedbacks for the products. However, if we talk about it was observed in both categories that peoplelike participate in different interaction provoking 
posts in some cases these posts are provided with a lucky draw or any prize-winning game but in some there was no reward but liked to interact. So, we can say that for clothing brands youth in Pakistan use social media mostly for just keeping themselves updated with new collections and offers.

However, for food brands they also use brand pages for sharing feedbacks as well. In depth Interview: Data was analyzed by using typology method, while analyzing the data transcripts were examined for emerging patterns and categories. Researcher analyzed transcripts developed from in depth interviews, coding of transcripts was performed and finally some themes emerged as a result of analysis and provided some specific motivations of youth for following brand pages andother usage of social media which include, Staying informed, refereed brands, feedback power.

\section{CONCLUSION}

This study concluded that youth in Pakistan are quite brand savvy people, and they follow and interact with brands in digital culture. However, from the analysis of data gathered through netnography and in-depth interviews as well; six motivations emerged out which influence the youth to follow and interact with brands at digital media which are: Staying informed, Referred brands, Feedback power, Entertainment, Self-expression and Pre-purchase information. They follow and interact with brands in digital culture, most importantly to stay informed about the products and offerings, they follow brand referred by friends or family, they like the power of sharing feedback on digital, they get entertained by participating in the games and activities shared by brands and enjoy winning prizes, they follow certain brands to portray their self-image considering that people see what they like or follow at their profile and they also read recommendations before buying the product.as it has been observed that digital media ,pertaining to ecommerce sites with social sites has influenced youth to attract and trigger on their perceptions for online buying, even brand advocates helps consumers to attain online buying for their personal as well as for their families which are very newly buying pattern especially in covid 19 .young consumers would like to go for online cloth buying as its new and attractive plus easiest way while using mobile phones with friends, families and having Facebook ,Instagram install on their mobile.As digital media sites like Facebook and Instagram are information, knowledge-seeking, maintaining brand relationships, social interaction, entertainment, self-expression, social influence, and communication. These findings are beneficial to marketers that wish to promote their products to mothers through digital media. The study discovered that there has been a considerable change in customer behavior when compared to past polls.

\section{REFERENCES}

Acar, O., \& Puntoni, S. (2016), "Customer empowerment in the digital age". Journal ofAdvertising Research, 56(1), pp. 4-8.

Blumler, J. G. (1979). "The role of theory in uses and gratifications studies". Communication Research, 6(1), 9-36

Chicca, J., \& Shellenbarger, T. (2018a), "Connecting with Generation Z: Approaches in Nursing Education". Teaching and Learning in Nursing, 13, 180-184

Fournier, S. (1998), "Consumers and their brands: developing relationship theory in consumer research". Journal of Consumer Research, 24(4), 343-353.

Jensen, K.B. (Ed.) (2013), "Media effects: quantitative traditions", A Handbook of Media and Communication Research: Qualitative and Quantitative Methodologies, Routledge, London.

Kelly, L., Kerr, G., \& Drennan, J. (2010),"Avoidance of advertising in social networking sites: The teenage perspective". Journal of Interactive Advertising, 10(2), 16-27.

Kim, A. J., \& Ko E. (2012), "Do social media marketing activities enhance customer equity? An empirical study of luxury fashion brand". Journal of Business Research, 65, 1480-1486.

Kozinets, R.V. (2002), "The field behind the screen: using netnography for marketing research in online communities". Journal of Marketing Research, 39(1), 61-72 London.

(2010). Netnography: Doing Ethnographic Research Online, Sage Publications,

(2015). Netnography: Redefined, Sage Publications, London.

Mangold, W. G., \& Faulds, D. J. (2009). Social media: The new hybrid element of the promotion mix". Business Horizons, 52, 357-365.

Momoko, F., Paul, H., \& Geoffrey N. S., (2019) "The strategic co-creation of content and student 
experiences in social media: An identity theories perspective". Qualitative Market Research: An International Journal, 22(1), 50-69

Muntinga, D. G., Moorman, M., \& Smit, E. G. (2011). Introducing COBRAs: Exploring motivations for brand-related social media use". International Journal of Advertising,30(1), 13-46.

Naaman, M., Becker, H., \& Gravano, L. (2011). Hip and trendy: Characterizing emerging trends on twitter". Journal of the American Society for Information Science and Technology, 62(5), 902 918.

Peters, K., Chen, Y., Kaplan, A. M., Ognibeni, B., \& Pauwels, K. (2013). Social media metrics. European Journal of Marketing, 42(3/4), 299-310

Raacke, J., \& Bonds-Raacke, J. (2008). My Space and Facebook: applying the uses and gratifications theory to exploring friend-networking sites". Cyber psychology and Behavior, 11(2), 169174.

Rodney, G. D. (2017) "Influence of social media marketing communications on young consumers' attitudes". Young Consumers, 18(1), 19-39,

Shao, G. (2009). "Understanding the appeal of user-generated media: a uses and gratification perspective". Internet Research, 19(1), 7-25.

Simmons, G. (2008). "Marketing to postmodern consumers: introducing the internet chameleon",

Singh, S., \& Sonnenburg, S. (2012). "Brand performances in social media". Journal of Interactive Marketing, 26(4), 189-197.

Stokes, R. (2013). e Marketing: The Essential Guide to Marketing in a Digital World, 5th ed., Quirk Education, Cape Town.

Teresa, T. \& José, L. (2019) "Understanding digital moms: motivations to interact with brands on social networking sites". Qualitative Market Research: An International Journal, 22(1), 7087

Whiting, A., \& Williams, D. (2013). "Why people use social media: a uses and gratifications approach". Qualitative Market Research: An International Journal, 16(4), 362-369. 